\title{
10 \\ EDUCAÇÃO E SAÚDE COMO PILARES NA FORMAÇÃO DO CIDADÃO: CONDIÇÕES DE HIGIENE EM UMA ESCOLA RURAL DO MUNICÍPIO DE UBERLÂNDIA-MG*1
}

\author{
Henrique Borges da Silva \\ Eloy Alves Filho \\ Maria Virginia Dias de Ávila
}

\section{Introdução}

A promoção da educação e de conhecimentos básicos em saúde na escola, por meio de uma prática educacional dialógica e reflexiva, pode levar ao conhecimento e à conscientização de como preservar a vida, resguardar a saúde da comunidade escolar e, por consequência, da sociedade como um todo.

A abordagem deste trabalho é por uma educação escolar e uma educação em saúde emancipadoras, em que os sujeitos envolvidos no processo tenham seus saberes valorizados, construam novos conhecimentos, para que possam atingir a autonomia e a cidadania plena em uma sociedade equitativa, pelo menos em educação e saúde.

A educação para a saúde e a educação popular em saúde envolvem um conjunto de práticas de educação para indivíduos e para a comunidade, a fim de aumentar a autonomia das pessoas e da comunidade para que possam fazer escolhas e adotar hábitos saudáveis de vida. Em consequência, intenta-se ações de preservação da saúde da escola, da família e do entorno.

$\mathrm{O}$ foco da educação em saúde e da medicina popular não é o de informar para a saúde, mas de transformar os saberes existentes em novos saberes e novas práticas. A educação, assim como as práticas educativas da escola, nessa perspectiva, busca o desenvolvimento da autonomia e da responsabilidade dos sujeitos na preservação da saúde, porém não mais pela imposição hegemônica de um saber técnico-científico detido pelo profissional de saúde, mas, sobretudo, pelo desenvolvimento da compreensão da situação de saúde e de sua importância para a sociedade (ALVES, 2005).

\footnotetext{
${ }^{*}$ DOI - 10.29388/978-65-86678-49-9-0-f.169-186

${ }^{1}$ Este capítulo é um recorte da Dissertação "As condições de higiene em uma escola rural do município de Uberlândia" defendida junto ao Programa de Pós-Graduação em Educação: Formação Docente para Educação Básica - Mestrado Profissional - UNIUBE/Uberlândia/MG.
} 
Salienta-se, ainda, que a estratégia das práticas educativas deve ser emancipadora, por meio de uma comunicação dialógica, que visa à construção de um saber sobre o processo saúde-doença-cuidado que possibilite aos indivíduos decidirem quais estratégias mais apropriadas para promover, manter e recuperar sua saúde (ALVES, 2005).

Torna-se relevante abordar a temática saúde e educação em país como o Brasil, cuja extensão territorial é vasta, o contingente populacional é grande e há uma considerável produção nos setores agrícola e industrial, contudo, ainda apresenta uma renda per capita baixa, se comparada aos padrões de países considerados de primeiro mundo.

Apesar do destaque do país no setor produtivo, a população, em maioria, apresenta uma injusta desigualdade social e baixo nível de escolaridade. Além disso, há uma carência de saneamento básico em grande parte do território, especialmente no meio rural, o que configura um atraso no desenvolvimento social e um comprometimento da saúde.

Tais fatores somados à precariedade do aparato governamental e aos parcos recursos destinados à educação e à saúde compõem um quadro bastante desanimador para o futuro imediato da nação. Todavia, sabe-se que o trabalho em promoção básica da saúde por meio da prevenção, mostra-se uma forma barata e eficiente de atenção em saúde e educação, desde que abraçada pela comunidade. O próprio Ministério da Saúde entende que "[...] é preciso desenvolver em cada um a capacidade de interpretar o cotidiano e atuar de modo a incorporar atitudes e/ou comportamentos adequados para a melhoria da qualidade de vida.". (BRASIL, 2011, p. 6).

Em razão disso, pesquisas que versam sobre a importância da promoção de higiene nas salas de aula da Educação Básica são pertinentes, pois poderão contribuir para a melhoria das ações relacionadas às práticas de higiene. A educação das crianças tornará um instrumento de promoção da saúde em suas próprias casas e nas comunidades. Para isso, utiliza-se o entusiasmo dos infantes para que tais ações sejam perpetuadas pelos pais, com impactos diretos na sociedade no que se refere às condições de saúde. O projeto de promoção da saúde nas casas, por meio das crianças, além de benéfico para as famílias, também o é para a nação, pois é de baixo custo para o poder público.

O trabalho aqui apresentado foi desenvolvido em uma escola pública da rede municipal de Uberlândia, a Escola Municipal Emílio Ribas, situada a, aproximadamente, 30 quilômetros do marco zero da cidade. Essa escola foi escolhida pela presença de crianças com idades entre cinco e dez anos, cuja higienização é, normalmente, deficitária e, em parte, dependente da atenção dos pais. 
A escola atende, em 2019, 163 alunos, distribuídos na educação infantil $\left(1^{\circ}\right.$ e $2^{\circ}$ períodos) englobando 28 alunos; no ensino fundamental I, englobando 66 alunos; e no ensino fundamental II (a partir do $6^{\circ}$ ano), contemplando 69 alunos.

Como participantes, foram selecionadas dez crianças entre cinco e nove anos, em razão da maior susceptibilidade dessa faixa etária em relação a doenças advindas da falta de higiene, visto que, muitas vezes, elas não conseguem realizar, satisfatoriamente, sua higienização corporal sozinhas.

Para traçar o perfil das famílias participantes em relação aos hábitos de higiene foi aplicado um questionário aos responsáveis legais pelas crianças participantes, nas suas próprias residências ${ }^{2}$. As respostas foram anotadas pelo primeiro autor. Em seguida, procedeu-se também à coleta de amostras de fezes e urinas para os exames laboratoriais ${ }^{3}$. Ressalta-se que esse procedimento foi coordenado pelo primeiro autor que é médico patologista, portanto, todos os cuidados de coleta e de análises foram resguardados.

Além disso, coletou-se também amostras da água oferecida aos alunos da escola para exames laboratoriais. Outro aspecto foi a observação dos banheiros em todas as visitas, a fim de verificar se a escola cumpria a Lei $\mathrm{n}$. 10.535/2010 que dispõe sobre a obrigatoriedade de oferta de sabão ou similares ou álcool em gel antisséptico para higienização das mãos.

Em razão do exposto, este capítulo tem por objetivo apresentar e analisar os principais hábitos de higiene praticados na Escola Municipal Emílio Ribas e no contexto familiar dos participantes da pesquisa.

Em relação à estrutura, este capítulo está organizado em três seções, além desta introdução e das referências. Na primeira, encontra-se uma breve contextualização acerca dos temas educação para a saúde e educação popular em saúde. Essa seção é seguida pela apresentação dos resultados e dos encaminhamentos. Por derradeiro, apresentam-se as considerações finais.

\section{Educação para a Saúde e Educação Popular em Saúde}

$\mathrm{Na}$ perspectiva de que educação e saúde estão imbricadas, a função da educação, de acordo com Freire (1996), é a de proporcionar que cada sujeito inserido no processo educativo possa exercer sua participação cidadã. Para ele, o ser humano consiste em um ser incompleto que tem uma vocação histórica para a humanização. Incompleto e consciente dessa inconclusão objetiva ser mais humanizado e mais gentificado, porém, depara-se com os fatores

\footnotetext{
${ }^{2}$ A pesquisa foi autorizada pelo Comitê de Ética em Pesquisa e todas as exigências de pesquisas que envolvem seres vivos e menores foram adotadas.

${ }^{3}$ Ressalta-se que, em todos os procedimentos da pesquisa, não acarretou em ônus para a escola, para a Secretaria Municipal de Uberlândia e para as famílias envolvidas na pesquisa.
} 
históricos que limitam e atrofiam a sua vocação ontológica de alcançar tais propósitos.

A educação é, nesse contexto, sinônimo de humanização, pois resulta no reconhecimento e na consciência da desumanização enquanto fato concreto e histórico, não como destino dado, mas como resultado de uma ordem injusta que produz a violência dos opressores e leva ao ser menos (FREIRE, 2011a).

Assim, a educação apresenta-se, primordialmente, como um ato político, que demarca a posição no mundo diante das realidades sociais e históricas já construídas e que, por isso mesmo, demanda novas atividades de intervenção, de rompimentos e de transformação social (FREIRE, 1993).

Em relação à educação contemporânea, Freire contribui com a concepção da prática educativa como uma prática libertadora de pensar, de refletir, de agir com liberdade na direção de emancipação coletiva e individual. Nas palavras de Freire (2011a), é dos oprimidos que pode surgir a libertação, tanto no aspecto educacional como no da saúde, pois estes não têm um compromisso com o sistema vigente que os oprime e, assim, a clareza política que vai se ganhando no processo histórico-dialético de construção das realidades sociais ajudará, significativamente, para formação de uma nova sociedade (STRECK; ZITKOSKI, 2010).

É por meio do processo educativo, ou seja, da educação, que a sociedade poderá ascender nos mais diversos aspectos e transformar-se em uma sociedade verdadeiramente autônoma. Juntamente com a educação, a saúde possui expressiva significação, uma vez que a qualidade de vida de um povo pode ser analisada pelos coeficientes de saúde e educação de seus cidadãos. Neste sentido, a educação em saúde consiste em dois polos que impulsionam a construção de uma associação promissora aos indivíduos.

A educação de qualidade e para todos, como entendida nesta pesquisa, prioriza a utilização de práticas educativas e preventivas inovadoras, consolidando a valorização dos saberes de todos os sujeitos envolvidos no processo educativo, reafirmando os saberes como geradores de conhecimento e mantenedores da saúde.

Pilon (2006) conceituou a Educação em Saúde como a promoção do desenvolvimento do ser humano, tendo como princípio um ambiente completo e incluindo as vertentes biológicas, psicológicas, sociais, econômicas e físicas que compreendem a sua existência. É considerada parte da qualidade de vida e não pode ser parcial ou fragmentada, ou corresponde à modificação total do ser humano e de seu projeto de vida ou nada acontece. Todos possuem habilidades e competências para desenvolver recursos pertinentes ao projeto de vida, a partir do que acredita ser significativo e importante para si.

A Fundação Nacional da Saúde, apresenta a Educação em Saúde como um processo organizado, constante e permanente que tem o intuito de 
promover a formação e o desenvolvimento da consciência crítica do cidadão, proporcionando encontrar soluções coletivas para os problemas vivenciados e a sua "real participação" no exercício do controle social (BRASIL, 2007).

Este marco teórico, proposto para Educação em Saúde, emprega metodologias baseadas na participação, em que a equipe de saúde e a população se relacionam em um processo de troca e acumulação de saberes e conhecimentos coletivos que penetrarão no indivíduo como um todo. Sendo assim, a grande dificuldade da educação em saúde é a promoção da qualidade de vida e as ferramentas para exercitar a consecução desses objetivos que são os democráticos e os valores humanísticos (OLIVEIRA et al., 2014).

Nesse cenário, a missão da educação não é dizer-lhes o que é mais ou menos importante, mas agir como facilitadora para que os próprios sujeitos enxerguem a importância das coisas, instigando-os a serem ativos no fenômeno da transformação. É preciso ter a noção de que a educação em saúde não é o mesmo que informação em saúde é, sobretudo, transformar saberes existentes. Ela busca promover mudanças de comportamento individual e coletivo, procurando também proporcionar mudanças de comportamento organizacional, capazes de trazer benefícios à saúde de camadas mais amplas da população (CANDEIAS, 1997).

É nessa dimensão da Educação em Saúde que os profissionais da área da saúde devem se comprometer de fato com a vida do outro. Sendo assim, é importante reorientar as práticas de saúde, na procura pela ampliação da capacidade de análise e de cogestão dos indivíduos, assim como da capacidade para lidar com as limitações individuais e impostas pelo contexto, para desenvolver uma prática construtiva e gradual, que busque proporcionar aos sujeitos que eles reconheçam e expressem seus interesses e seus desejos (FERNANDES, 2010).

Barroso, Vieira e Varela (2003) acreditam que a Educação em Saúde é concebida por meio da interdisciplinaridade e consiste em mais que uma atividade e sim uma atitude que implica reunir ações e realizações de atenção à saúde para alcançar fins comuns, com intuito de melhorar a qualidade de vida.

Freire (2005) nos enriquece dizendo que o processo educativo, ou seja, a educação se estabelece em aprender e ensinar, baseando-se em aprendizagem, construção e reconstrução. Sendo assim, não cabe aos educandos apenas ouvir explicações e informações e estabelecer uma posição ingênua diante dos conhecimentos e saberes adquiridos, mas se movimentarem procurando a transformação da realidade ao seu redor. Caso contrário, serão em vão os ensinamentos apresentados pelos docentes. A educação em saúde ajuda, significativamente, a aprendizagem e a conscientização das pessoas em relação aos diversos aspectos de uma doença e, em consequência, ajuda o desenvolvimento da promoção da saúde. 
Constata-se, assim, que a educação em saúde e a promoção da saúde estão interligadas e, quando bem aplicadas, podem promover a transformação de atitudes, de crenças, de valores, de medos, de angústias e de dúvidas. Portanto podem melhorar a qualidade de vida do sujeito, tanto em nível familiar quanto em nível de grupo social. A inserção de tais conceitos pode promover uma formação do profissional de saúde, reforçando a valorização do saber popular e respeito à autonomia do usuário (SABOIA, 2003).

O que diferencia a verdadeira educação é a premissa de que ela é um componente de intervenção política, caso contrário, não é educação. O político é colocado como elemento de formação que molda o indivíduo como operador da sua história. Assim, as classes populares constroem saberes relacionados às suas experiências de vida e ao contexto social do qual fazem parte.

Nesse contexto, deparamo-nos com um cenário de desafios e obstáculos em relação às diversidades e às afinidades culturais entre os diversos saberes na saúde, vindo à tona as diferentes visões sobre as articulações entre Políticas Públicas e Sociedade Civil. Isso ocorre, principalmente, quando se aumenta, em nível local e municipal, a rede institucionalizada de participação popular por intermédio de recomendações (VASCONCELOS, 2001).

A educação popular teria a função então de reconhecer e problematizar esses saberes, sem subjugá-los pelos saberes técnico-científicos, entretanto relacionando um ao outro. Sendo assim, a Educação Popular consiste em uma nova teoria, não apenas de educação, mas das interpelações, entre sua prática e um trabalho político progressivamente popular de interação entre os sujeitos e a sociedade. Objetiva fazer ainda não apenas um método de trabalho "com o povo" por meio da educação, mas uma nova educação libertadora, por meio do trabalho do e com o povo (BRANDÃO, 2006).

A problematização usada pela Educação Popular tem como pilar uma maneira de apresentar, processar e produzir o conhecimento diferente, que tem como partida o pressuposto da incompletude de todos os saberes. Para sua sobrelevação, não basta somente procurar a interdisciplinaridade e as falas de especialistas no tema para a elaboração do conhecimento necessário, mas também, e especialmente, a valorização e ressignificação dos saberes dos sujeitos, dos moradores e dos movimentos sociais envolvidos no processo.

Esses saberes valorizados pela Educação Popular não são somente conhecimentos logicamente elaborados e organizados, mas também saberes de outra natureza, como os saberes oriundos da intuição, da sensibilidade e da emoção que nascem na arte, na vida espiritual, nas relações amorosas, na apreciação, nas brincadeiras, nas festas e na agressividade. É interessante a maneira como as classes populares latinoamericanas e seus movimentos sociais tornam-se ricos e ficam à vontade quando esses outros saberes são acolhidos e valorizados (BATISTA, 2012). 
$\mathrm{Na}$ Educação Popular, a problematização não se encerra no encontro coletivo de uma solução. Ela prossegue na sua aplicação no contexto do sujeito, proporcionando o surgimento de novos desafios e reflexões. Os resultados da atividade, com suas insuficiências, produzem novas problematizações. Os sucessos e os fracassos inesperados ensinam aspectos antes não considerados. Trata-se, portanto, de uma problematização articulada com a realidade e comprometida com sua modificação, o que não ocorre em muitas metodologias problematizadoras que são apresentadas na área da saúde.

A participação ativa de grupos sociais, antes calados, questiona e cria oposições a projetos tecnicamente muito bem preparados, irritando gestores das políticas sociais que costumam ficar isolados nos órgãos de planejamento. Assim, a proclamada valorização da participação popular nas políticas sociais não é ainda uma realidade autenticamente buscada no cotidiano dos serviços, por ser demais perturbadora da lógica dominante (VASCONCELOS, 2009).

O movimento de educação popular na área da saúde, no Brasil, surgiu durante a ditadura militar, época marcada pela restrição dos direitos civis por parte dos governantes. Por outro lado, esse período foi também marcado pela luta, liderada por parte dos militantes de movimentos sociais, intelectuais, artistas, estudantes e lideranças da Igreja progressista, em prol da democracia, da liberdade de expressão e da garantia dos direitos civis.

Apesar dos primeiros movimentos em prol da transformação das relações na área da saúde, a educação popular é incorporada nesse campo, mais decisivamente, na década de 70 do século XX por intermédio de pessoas inseridas nas comunidades de base popular no seio da Igreja Católica, em particular os adeptos dos saberes de Paulo Freire e Leonardo Boff. Esse último é um dos responsáveis pela formulação da Teologia da Libertação, linha de pensamento que é o oposto às ideias autoritárias e conservadoras da Igreja (ORTUNES; MARTINHO; CHAIA, 2019).

A partir da década de 70, muitas mudanças ocorrem no Brasil, como o término da ditadura civil-militar e a consequente abertura para a democracia. Foi um processo lento e cheio de disputas entre os que defendiam e os que se opunham aos modelos baseados no autoritarismo.

Ainda nos anos 70, privilegiou-se a materialização da participação pública na dinâmica do funcionamento e no oferecimento dos serviços de saúde. Até o início da década, era baixo o grau de organização dos setores populares subordinados, resultado da ditadura militar do nosso país. Ressalta-se que, na década de 1970, a situação política nacional, que consistia em uma liberdade muito restrita com ausência de democracia e de participação na política, fez com que diversas propostas de participação da comunidade fossem arquivadas. Algumas experiências, porém, foram transformadas em práticas de organização e politização comunitária gerando oposição à situação dominante, 
na perspectiva da reforma do setor de saúde no Brasil (VALLA; STOTZ, 1994).

Nesse cenário de crise da sociedade, por conta da ditadura civil-militar e, consequentemente, no sistema de saúde, nasce uma forma diferente de participação da população no país: a participação popular. Nesse tempo, a proposta da medicina comunitária teve uma nova interpretação, haja vista $\mathrm{O}$ limite das ações que permeiam a conquista da saúde pelas classes mais populares. A participação popular tem o objetivo de combater o Estado e representa o aprofundamento da crítica e a radicalização das práticas políticas de oposição ao sistema que está no poder. A categoria comunidade é substituída pela categoria povo, que é representado por uma parte da população excluída do acesso aos bens e serviços (CARVALHO; PETRIS; TURINE, 2001).

A questão de a saúde ser um direito é apresentada em termos da premissa de que a solidariedade social, como apresenta o artigo $196 \mathrm{da}$ Constituição Federal, decreta políticas socioeconômicas que direcionam para a redução do risco de doenças e outros agravos à saúde (STOTZ, 2004).

Vasconcelos (2001) nos apresenta que, se o estado se modificou, os movimentos sociais também se modificaram neste percurso e passaram de uma posição basicamente de contestação para uma posição de negociação, afirmando o caráter contraditório do estado de apresentar diversos interesses e alianças, que passam a se aperfeiçoar tecnicamente no sentido da possibilidade de acompanhar e direcionar os serviços e os benefícios conquistados.

Em 2003, é iniciado um processo de conjuntura de movimentos e práticas de educação popular em saúde. Esse processo foi desenvolvido em conjunto com a rede de educação popular em saúde e movimentos nacionais como o dos Sem Terra (MST), o Movimento Popular de Saúde (MOPS), a Direção Executiva dos Estudantes de Medicina, o Movimento de Reintegração dos Portadores de Hanseníase (MORHAN) dentre outros movimentos coletivos de base popular. Segundo o Relatório de 2002 da Articulação Nacional de Movimentos e Práticas de Educação Popular em Saúde (ANEPS), um dos seus objetivos centrais é a elaboração de uma nova forma de diálogo com os governos na construção de uma agenda pública no setor saúde (OLIVEIRA, 2009).

O desenho da ANEPS consiste em quatro segmentos de atuação: a educação, a comunicação, a articulação e a pesquisa. Isso ocorreu com intuito de tentar responder às demandas dos movimentos constituintes da ANEPS e versava sobre os problemas apresentados em oficinas nacionais e locais como a sensível articulação conceitual com a educação popular no setor saúde. A pouca representatividade das práticas populares em saúde, o embrionário processo de relação e o diálogo entre os movimentos e práticas populares entre si, com a 
academia e serviços de saúde e a inexistência de estudos sistematizados caracterizavam questões problema para a ANEPS (OLIVEIRA, 2009).

A Educação Popular em Saúde, ao estimular autonomias baseadas na individualidade e na coletividade, possibilita a alteridade entre indivíduos e movimentos sociais na luta por direitos, auxiliando na ampliação do significado dos direitos de cidadania e instituindo o seu crescimento (BRASIL, 2007).

\section{Resultados e encaminhamentos}

A pesquisa de campo teve início com a visita à Escola Municipal Emílio Ribas, com o propósito de conhecer o seu espaço físico para vislumbrar ações que pudessem colaborar na promoção e na manutenção da higiene da comunidade escolar.

O aspecto do bebedouro foi considerado satisfatório, tendo em vista que a escola dispunha de um bebedouro industrial com dispositivo para filtragem e para resfriamento da água para o consumo dos alunos, dos funcionários e do corpo docente.

Apesar do aspecto satisfatório, realizou-se uma coleta da água para exames laboratoriais. Tal procedimento foi motivado pelo fato de a água da escola não estar conectada ao sistema municipal de abastecimento urbano, pois é proveniente de poço artesiano. Para a análise da água, contratou-se uma empresa privada, a qual avaliaria diversos parâmetros. Ressalta-se que este exame não gerou ônus para a escola nem para a Prefeitura Municipal de Uberlândia.

A empresa escolhida é parceira da Faculdade de Química da Universidade Federal de Uberlândia (UFU), a qual realizou diversas análises em concordância com a Associação Brasileira de Normas Técnicas (ABNT). Foi enfatizado a microbiologia, a presença de metais pesados e a composição química, principalmente a distribuição de eletrólitos, tendo na quantidade de fluoreto o fator mais relevante. Justificamos a opção por uma empresa privada devido à neutralidade, evitando-se qualquer possível viés político em caso do uso do aparato municipal.

Alguns resultados da análise são considerados preocupantes. Constatou-se, primeiro, a presença de coliformes totais na água, provavelmente, em função de esgoto não tratado das casas nas cercanias e dos dejetos biológicos das agroindústrias próximas. Em segundo, a quantidade insuficiente de flúor para a prevenção da cárie. Os coliformes totais são bacilos gram negativos, aeróbios ou eventualmente anaeróbios. Eles sobrevivem sem oxigênio e pertencem aos gêneros Klebisiella, Enterobactos, Escherichia, Citobacter e outros. 
Os grupos de bactérias citadas acima são considerados significativos marcadores de contaminação da água, já que são encontrados nas fezes de mamíferos em geral e são facilmente detectáveis. Destacam-se como agentes patogênicos o gênero Klebsiella, responsável por gastroenterites e pneumonias em imunocomprometidos, especialmente alcoólatras; Enterobacter e E.coli, relacionada a infecções urinárias e enterites potencialmente graves.

O Ministério da Saúde, por meio da Portaria no 2914/2011, também chamada de Portaria da Potabilidade, determina que a água potável humana não deve conter coliformes totais, ainda que essas bactérias não sejam patogênicas (causadoras de doenças), em sua maioria.

Caso ocorra a presença dessas bactérias, o Ministério da Saúde recomenda, por meio da ANVISA (Agência Nacional de Vigilância Sanitária), o tratamento da fonte da água para readequá-la ao consumo humano, caso haja duas amostras positivas em um mês. A presença de E.coli na água, devido a sua virulência, é considerada sempre um acontecimento mais grave, devido ao maior risco de doenças e mais possibilidade de contaminação dos consumidores.

Embora a maior parte dos parâmetros estivessem dentro dos limites da normalidade, a presença de coliformes no lençol d'água, ainda que não patogênicos, demonstrou possível contaminação por esgoto doméstico, proveniente das casas ao redor da escola e de rejeitos da agroindústria nas proximidades.

Mesmo os coliformes encontrados não sendo considerados patogênicos, a ANVISA considera que, após uma amostra positiva para coliformes totais, deve ser realizada nova coleta no intervalo de um mês. Em caso de duas amostras contaminadas em um mês, a ANVISA recomenda a suspensão do abastecimento de água local até que haja a descontaminação.

No caso da Escola Municipal Emílio Ribas, trata-se de problema grave e de difícil solução imediata, já que há a impossibilidade de deslocamento da escola, das casas das comunidades próximas e da indústria local. As dificuldades óbvias de instalação de rede de esgoto em áreas tão amplas e a relativa impossibilidade de descontaminação da fonte de água nos levam a pensar em soluções alternativas mais simples e mais baratas.

Dentre as inúmeras possibilidades de tratamento da água, destaca-se a aplicação do hipoclorito de sódio, devido ao seu baixo custo e alto índice de eficácia. Ao mesmo tempo em que é uma forma eficaz e barata de descontaminação, o hipoclorito de sódio é vendido comercialmente como água sanitária, portanto pode ser a melhor solução a ser aplicada.

Como mencionado, a desinfecção do lençol freático é uma tarefa difícil e cara, no entanto, nossa proposta se baseia tão somente no uso de hipoclorito de sódio no reservatório de água oferecida aos alunos. A solução deve ser 
aplicada entre 2 e 2,5\%, bastando duas gotas por litro, deixando agir por, pelo menos, 30 minutos antes do consumo (BRASIL, 2011).

Esta alternativa, se bem ministrada, é eficiente e barata para desinfecção da água. Em razão disso, foi enviado um ofício à direção da escola, e outro, à Prefeitura Municipal, como sugestão para o tratamento da água com base nesse processo de introdução do hipoclorito de sódio.

Outro fato grave foi identificado nos banheiros destinados ao uso dos alunos e das alunas, isto é, não havia sabonete disponível para a higienização das mãos. Esse fato foi reparado e constatado nas dez visitas realizadas à escola. A não oferta de sabonete pela escola contraria a Lei n. 10.535, de 2010, da Prefeitura Municipal de Uberlândia que prevê, em seu Art. $1^{\circ}$, que

Os estabelecimentos públicos e privados que prestam serviços ao público, ficam obrigados a instalar ou disponibilizar produtos sanitizantes, antissépticos, higiênicos ou similares para a higienização e/ou assepsia das mãos dos usuários, clientes e funcionários, tais como: (...) IX - sabonete antimicrobial; X - sabonete espuma; XI - sabonete mousse; XII - sabonete líquido; XII - sabonete em barra; XVI - sabão neutro. (UBERLÂNDIA, 2010, p. 5)

Os alunos procediam à higienização das mãos apenas lavando-as com a água da torneira do banheiro, portanto não utilizavam nenhum produto sanitizante ou quaisquer similares para assepsia das mãos.

Para conhecer os participantes e suas famílias, foram realizadas algumas visitas a suas residências. Inicialmente, com o consentimento assinado pelos pais, foi realizado um exame físico geral com pesagem dos discentes participantes e preenchido um questionário com perguntas direcionadas aos pais. Esses dois procedimentos foram realizados na casa de cada criança, visando à coleta de dados demográficos, socioeconômicos e de condições de saúde e de higiene dos participantes. Como complemento, foram realizados, nas crianças selecionadas, com a anuência dos pais, exames de urina e fezes, sem quaisquer ônus para as famílias. Tinha-se a pretensão, com esses exames, de detectar possíveis doenças infectoparasitárias comumente relacionadas à falta de higiene.

Os questionários respondidos pelos responsáveis pelos discentes possibilitaram traçar o perfil dos participantes. Constatou-se, portanto, que a renda média familiar variava entre um e três salários mínimos. Os adultos, basicamente, são hortifruticultores, funcionários na agroindústria local ou auxiliar de serviços gerais. Embora simples, a maioria das residências contavam com condições mínimas de habitabilidade, exceto em uma delas, construída com restos de madeira e lona, sem piso e sem forro, apesar de contar com banheiro interno e fossa séptica. 
Ainda sobre o perfil das famílias, verificou-se que, em média, há quatro habitantes por residência e a idade dos adultos varia entre 23 a 43 anos. As casas possuem, em média, cinco cômodos com, pelo menos, um banheiro interno. Quando perguntado sobre quantos banhos as crianças tomam por dia, obteve-se como resposta que variava entre duas a três vezes por dia. Da mesma forma, a quantidade de escovação diária dos dentes também está entre duas ou três vezes. Foi relatado também que os pais, normalmente, não ajudavam as crianças na hora do banho, tampouco na escovação dos dentes.

Das casas pesquisadas, seis delas contam com poço semiartesiano para abastecimento de água e a maior parte das crianças não possuía histórico de doenças infectoparasitárias. O nível de escolaridade dos pais, em sua maior parte, é do $6^{\circ}$ ao $9^{\circ}$ ano do Ensino Fundamental, porém três das mães possuem o Ensino Médio. Sobre a renda familiar mensal, na maioria dos questionários, somando o rendimento de todas as pessoas que residem na casa, a média foi de um a três salários mínimos.

$\mathrm{Na}$ residência mais precária visitada, o abastecimento de água se fazia por meio do bombeamento de água oriunda do rio Uberabinha diretamente para a casa. Ressalta-se que a água é utilizada pela família sem um tratamento adequado.

Ao se contrastar as respostas dos pais às questões do questionário com a realidade observada, constatamos algumas discrepâncias. Eventualmente, pudemos perceber que as afirmações dos pais acerca dos cuidados de higiene para com as crianças não correspondiam à realidade, como, por exemplo, a quantidade de escovações diárias dos dentes. Outro aspecto foi observar que, embora os pais relatassem que as crianças tomavam dois a três banhos diários, não correspondia à realidade, isso porque algumas crianças estavam com aspecto de que não tomavam banho há horas.

Foi realizado também, em todas as crianças, exame parasitológico de fezes (EPF) e exame simples de urina (EAS), a fim de investigar se elas possuíam alguma doença infectoparasitária que pudesse ser atribuída à falta de higiene. Entretanto, todos os exames se mostraram negativos, mesmo aqueles das crianças em condições habitacionais mais precárias. Foi entregue a todos os pais, como acordado com eles, juntamente com a direção da escola, uma cópia do resultado dos exames realizados nas crianças participantes.

Após análise da situação da escola, dos exames de fezes e urina realizados com o material dos alunos participantes e da análise da qualidade da água oferecida à comunidade da escola, algumas ações foram traçadas como proposta de intervenção.

Com relação ao processo de higienização das mãos, foi sugerido à escola um trabalho educativo por meio de vídeos infantis e de fácil compreensão direcionado, especialmente, para as crianças do ensino 
fundamental I. Dentre os temas, destacam-se a importância da higienização correta das mãos antes de todas as refeições para prevenir doenças provocadas por micro-organismos como fungos e bactérias. Reforçou-se também a importância de escovação dos dentes para eliminar resíduos de alimentos da boca e enfatizou-se que a água pode ser contaminada por bactérias eliminadas pelas fezes dos mamíferos, daí a importância de tratar a água para o consumo humano. Por fim, apresentaram-se sugestões sobre hábitos de higiene como tomar banho diariamente, lavar os alimentos, lavar as mãos, dentre outros.

A conscientização sobre a necessidade de hábitos diários e constantes de higiene é primordial para que os alunos socializem tais noções para o restante da família e para a vizinhança.

Para que esta proposta seja cumprida, seria fundamental que a Prefeitura Municipal de Uberlândia cumprisse a lei e providenciasse, para as escolas, meios para higienização das mãos. Portanto, foi enviado à prefeitura um ofício solicitando que a Lei n. 10.535, de 2010 fosse cumprida.

Contrariando um dos pressupostos de que, provavelmente, as crianças portariam algum tipo de verminose, as análises dos materiais deram negativas. Ressalta-se, com uma dose de otimismo, que, apesar de as condições de higiene na escola não serem as ideais e, as residências estarem aquém do desejável, ou até mesmo precárias, as crianças, felizmente, apresentavam bom estado de saúde e, por via de consequência, não estavam sendo prejudicadas no processo de ensino e aprendizagem.

Consideramos a contribuição deste trabalho de maior importância, pois os desdobramentos da pesquisa afetarão diretamente a comunidade escolar e, de forma indireta, toda a comunidade circundante da escola, uma vez que melhorará de maneira efetiva na qualidade da água ofertada aos alunos e, como consequência, diminuir a incidência de doenças.

Em suma, a educação para a saúde e a educação popular em saúde, como apregoados, envolvem um conjunto de práticas de educação para indivíduos e para a comunidade, a fim de aumentar a autonomia das pessoas e da comunidade para que possam fazer escolhas e adotarem hábitos saudáveis de vida. Esta foi a intenção ao desenvolver as análises da água, exames das crianças, ações de preservação da saúde da escola, da família e do entorno.

\section{Considerações Finais}

Do ponto de vista prático, a educação e a saúde em nosso país têm evoluído de forma muito lenta, já que basta nos lembrarmos dos dados obtidos sobre a taxa de esgoto das residências brasileiras e o fraco desempenho de nossos alunos dos ensinos fundamental e médio em comparação com os países desenvolvidos. 
Desta maneira, algumas constatações acerca das condições de renda das famílias dos alunos da Escola Municipal Emílio Ribas e da insuficiente atuação do poder público na promoção da higiene e saúde podem ser consideradas bastante preocupantes para uma cidade do porte de Uberlândia. O abismo se acentua quando comparamos saúde e educação em nosso país, com os países considerados modelos em termos de bem-estar social, por exemplo, os escandinavos, cuja extensão territorial é menor que a do Brasil.

Conforme mencionado, foram realizadas cerca de vinte visitas à Escola Municipal Emílio Ribas, tendo sido constatados diversos aspectos que deixaram a desejar, de maior ou menor gravidade. A ausência de sabonete ou de outros produtos para a higienização das mãos é uma falta grave e um fragrante desrespeito à lei Municipal n. 10.535, de 09 de agosto de 2010.

A ausência do Programa de Saúde na escola rural de Uberlândia também poderia ser resolvida sem grandes problemas, bastando vontade política, pois o mesmo programa já fora implementado na zona urbana da cidade há mais de dez anos.

A água oferecida à escola pode ser considerada a questão mais grave a ser resolvida, tanto do ponto de vista microbiológico, pela contaminação do lençol freático por coliformes, quanto pela ausência da quantidade mínima de flúor recomendada pelo próprio Ministério da Saúde.

Todas estas demandas remetem de maneira direta à formulação dos produtos a serem oferecidos como soluções e/ou sugestões no intuito de colaborar com a comunidade local e auxiliar outras escolas rurais, provavelmente, em condições semelhantes.

Este trabalho, embora de proporções pequenas, pode contribuir com a Educação Básica, porém ele não se esgota aqui. Fica, então, aberto para que novos pesquisadores possam continuar esta proposta com a finalidade de colaborar com a educação e com a melhor qualidade de vida da população.

O foco da educação em saúde, como apresentado ao longo do texto, não é o de informar para a saúde, mas de transformar os saberes existentes em novos saberes e novas práticas. A educação, assim como as práticas educativas sugeridas à escola, durante e ao final da pesquisa, assim como as orientações técnicas buscam o desenvolvimento da autonomia e da responsabilidade dos sujeitos que compõem a comunidade escolar na preservação da saúde e na educação de qualidade e equitativa. 


\section{Referências}

ALVES, V. S. Um modelo de educação em saúde para o Programa Saúde da Família: pela integralidade da atenção e reorientação do modelo assistencial. Interface, Botucatu, v. 9, n. 16, p. 39-52, feb. 2005. Disponível em: http://www.scielo.br/scielo.php?script=sci_arttext\&pid=S141432832005000100004\&lng=en\&nrm=iso. Acesso em: 23 abr. 2020.

BARROSO, G. T. VIEIRA, N. F. VARELLA, Z. M. V. (org.). Educação em saúde: no contexto da promoção humana. Fortaleza: Edições Demócrito Rocha, 2003.

BATISTA, P. S. S. Ética no cuidado em saúde e na formação universitária na perspectiva da Educação Popular. 2012. 196 f.Tese (Doutorado em Educação) - Programa de Pós-Graduação em Educação. Universidade Federal da Paraíba, João Pessoa, 2012.

BRANDÃO, C. R. Educação Popular. São Paulo: Brasiliense. 2006.

BRASIL. Portaria No. 2.914, de 12 de dezembro de 2011. Ministério da Saúde. Disponível em:

https://bvsms.saude.gov.br/bvs/saudelegis/gm/2011/prt2914_12_12_2011.ht ml. Acesso em: 7 ago. 2021.

BRASIL. Fundação Nacional de Saúde. Diretrizes de educação em saúde visando à promoção da saúde: documento base - documento I/Fundação Nacional de Saúde. Brasília: Funasa, 2007a.

BRASIL. Ministério da Saúde. Secretaria de Gestão Estratégica e participativa. Departamento de Apoio à Gestão Participativa. Caderno de educação popular e saúde. Brasília, DF: Ministério da Saúde, 2007b.

BRASIL. Ministério da Saúde. Secretaria de Atenção à Saúde. Departamento de Atenção Básica. Passo a passo PSE: Programa Saúde na Escola: tecendo caminhos da intersetorialidade. Brasília: Ministério da Saúde, 2011.

CANDEIAS, N. M. F. Conceitos de educação e de promoção em saúde: mudanças individuais e mudanças organizacionais. Rev. Saúde Pública, São Paulo, v. 31, n. 2, p. 209-213, abr. 1997. Disponível em: http:/ / www.scielo.br/scielo.php?script=sci_arttext\&pid=S003489101997000200016\&lng=en\&nrm=iso. Acesso em: 06 jan. 2020.

CARVALHO, B. G.; PETRIS, A. J.; TURINI, B.; Controle social em saúde. In: ANDRADE, S. M.; SOARES, A. D.; CORDONE JUNIOR, L. (org.). Bases da saúde coletiva. Londrina: UEL, 2001. p. 55-83. 
FERNANDES, S. C. A. As práticas educativas na saúde da família: uma cartografia simbólica. 2010. 254 f. Tese (Doutorado em Desenvolvimento Regional; Cultura e Representações) - Programa de Pós-Graduação em Ciências Sociais. Universidade Federal do Rio Grande do Norte, Natal, 2010.

FREIRE, P. Política e educação: ensaios. São Paulo: Cortez,1993.

FREIRE,P.. Pedagogia da Autonomia: saberes necessários à prática educativa. São Paulo: Paz e Terra, 1996.

FREIRE,P. Pedagogia do Oprimido. Rio de Janeiro: Paz e terra, 2005.

FREIRE,P.. Pedagogia do oprimido. Rio de Janeiro: Paz e Terra. 2011.

OLIVEIRA, L.C. et al. Participação popular nas ações de educação em saúde: desafios para os profissionais da atenção primária. Interface, Botucatu, v. 18, p. 1389-1400, 2014. Disponível em: http://www.scielo.br/scielo.php? script $=$ sci_arttext\&pid=S1414-32832014000601389\&lng=en\&nrm=iso. Acesso em: 03 jan. 2020.

OLIVEIRA, M. W. Apresentação - Educação nas práticas e nas pesquisas em saúde: contribuições e tensões propiciadas pela educação popular. Cad. CEDES, Campinas, v. 29, n. 79, p. 297-306, dez. 2009. Disponível em: http://www.scielo.br/scielo.php?script=sci_arttext\&pid=S010132622009000300001\&lng=en\&nrm=iso. Acesso em: 02 jan. 2020.

ORTUNES, L.; MARTINHO, S.; CHAIA, V. Lideranças políticas no Brasil: da Teologia da Libertação ao Neofundamentalismo. Rev. Bras. Ciênc.

Polít., Brasília, v. 1, n. 28, p. 195-232, abr. 2019. Disponível em: http://www.scielo.br/scielo.php?script=sci_arttext\&pid=S010333522019000100195\&lng=en\&nrm=iso. Acesso em: 02 jan. 2020.

PILON, A. F. Construindo um mundo melhor: A abordagem ecossistêmica da qualidade de vida. Revista Brasileira em Promoção da Saúde, v. 19, n. 2, 2006. Disponível em: https://www.redalyc.org/articulo.oa?id=40819207. Acesso em: 06 jan. 2020.

SABOIA, V. M. Educação em saúde: a arte de talhar pedras. Niterói: Intertexto, 2003.

STOTZ, E. N. Os desafios para o SUS e a educação popular: uma análise baseada na dialética da satisfação das necessidades de saúde. In: MINISTÉRIO DA SAÚDE. VER-SUS Brasil: Cadernos de textos. 2004. p. 284-299. Disponível em: http://bvsms.saude.gov.br/bvs/publicacoes/CadernoVER_SUS.pdf. Acesso em: 02 jan. 2020. 
STRECK, D. R.; ZITKOSKI, J. J. Teses centrais da pedagogia freiriana. São Paulo: Segmento, 2010.

UBERLÂNDIA. Lei $\mathbf{n}^{\mathbf{0}} \mathbf{1 0 . 5 3 5}$, de 08 de abril de 2010. Dispõe sobre a obrigatoriedade de instalação de recipientes com álcool gel antisséptico ou produtos similares, nos estabelecimentos. Uberlândia: Sistemas de Leis Municipais, [2010]. Disponível em:

https://leismunicipais.com.br/a1/mg/u/uberlandia/lei-ordinaria/2010/1054/ 10535. Acesso em: 07 jan. 2020.

VALLA, V. V; STOTZ, E. N. Educação, saúde e cidadania. Petrópolis: Vozes, 1994.

VASCONCELOS, E. M. A participação popular e educação nos primórdios da saúde pública brasileira. In: VASCONCELOS, E. M. (org.). A saúde nas palavras e nos gestos: reflexões da Rede de Educação Popular e Saúde. São Paulo: Hucitec, 2001.

VASCONCELOS, E. M. Para além do controle social: a insistência dos movimentos sociais em investir na redefinição das práticas de saúde. In: FLEURY, S.; LOBATO, L. V. C. (org.). Participação, democracia e saúde. Rio de Janeiro: Cebes, 2009. 